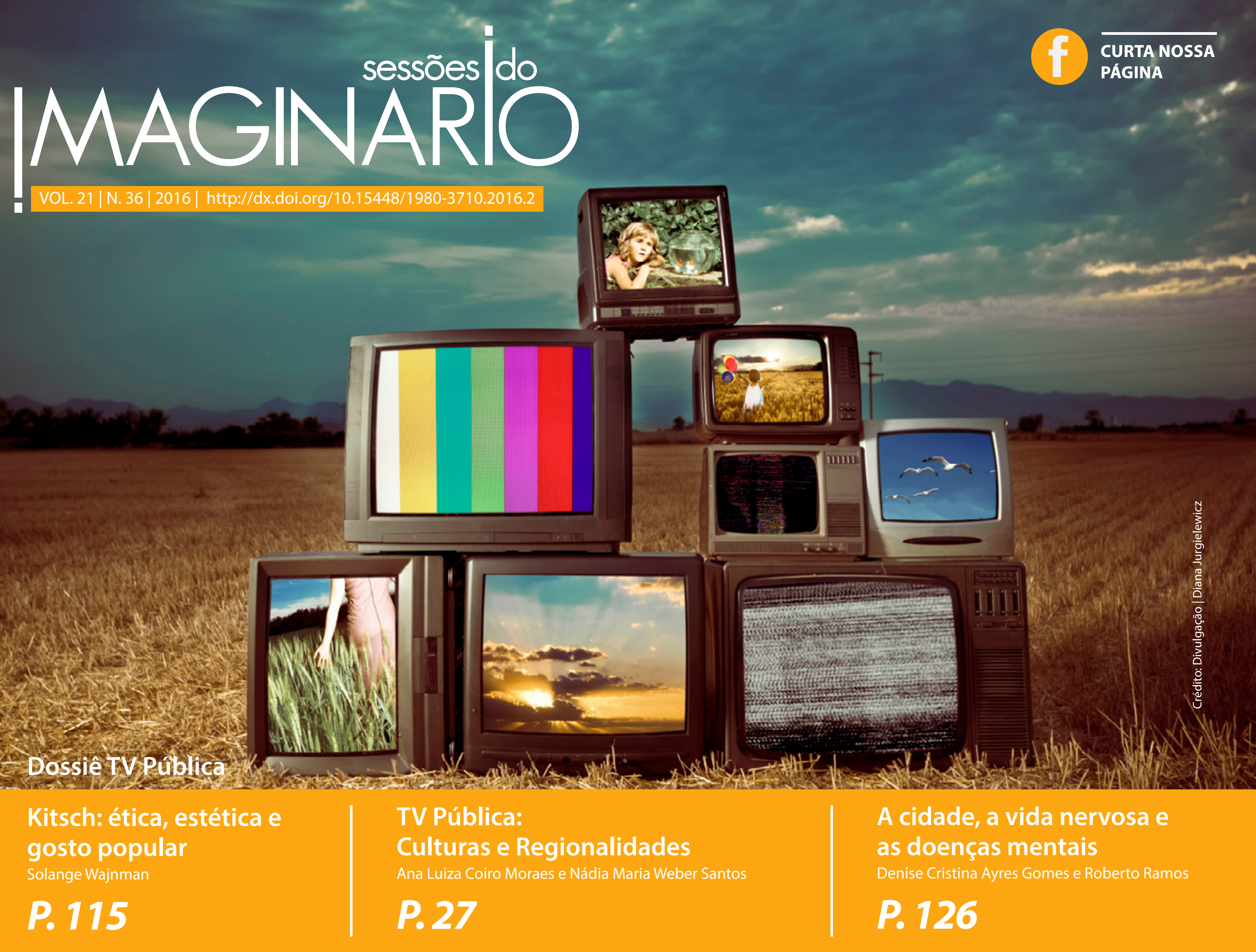




\section{TV Brasil e a configuração da rede nacional de televisão pública na Região Sul}

TV Brasil and the setting of national public television network in the South

Ivonete da Silva Lopes ${ }^{1}[3$

\section{DOSSIÊ}

\section{Resumo}

Este artigo discute um dos princípios constitutivos da radiodifusão pública, a universalidade de acesso, a partir da análise da cobertura geográfica da rede nacional de televisão pública na Região Sul. Destaca que a região possui a segunda maior quantidade de emissoras públicas do país, 28 TVs Educativas, no entanto apenas quatro delas integram a rede pública liderada pela TV Brasil. O cenário indica que universalizar a cobertura ainda representa um desafio a ser superado pela TV Brasil quase uma década depois de sua implantação.

\section{Palavras-chave}

Televisão pública; universalidade; TVs educativas; Região Sul.

\section{Abstract}

This article discusses one of the constituent principles of public broadcasting, the universality of access from the analysis of the national network coverage public television led by TV Brazil in the South. It highlights that the region has the second largest amount of public broadcasters in the country, 28 Educational TVs, but only four of them are part of the public. The scenario indicates that universal coverage is still a challenge to be overcome by TV Brazil nearly a decade after its implementation.

\section{Keywords}

Public television; universality; education TV's; South Region. 


\section{Introdução}

A comunicação pública brasileira foi reorganizada com a constituição da Empresa Brasil de Comunicação (EBC), em 2007. A empresa reúne sete emissoras de rádio, três agências de notícias e duas emissoras de televisão: a TV Brasil Internacional e a TV Brasil - emissora aberta, generalista e com aspiração de coordenar a rede nacional de comunicação televisão pública. A cobertura nacional foi prevista por meio de uma estrutura formada por emissoras próprias (Rio de Janeiro, Brasília, Maranhão e, posteriormente, São Paulo) e da afiliação das TVs Educativas - emissoras que somam cerca de 150 estações distribuídas por todo o país.

A afiliação foi a alternativa encontrada diante da dificuldade da emissora chegar aos municípios brasileiros através de estrutura própria, conforme afirmou a primeira presidente da EBC, Tereza Cruvinel, "[...] seria praticamente impossível, no sistema analógico, prover a TV Pública de uma rede de canais que cobrisse todo o país [...] (Cruvinel, 2011, pp. 51-52). Passada quase uma década da criação da TV Brasil, a afiliação não tem se mostrado um processo simples para ampliar a cobertura no país diante da resistência dos concessionários de TVs Educativas em integrar a rede pública liderada pela TV Brasil.

Diante deste contexto, o presente artigo reflete sobre a universalidade da cobertura da radiodifusão pública como um dos seus princípios mais relevantes e aponta as dificuldades encontradas pela TV Brasil para formar a rede pública. Analisa-se o complexo cenário na Região Sul, onde existem 28 TVs Educativas, a segunda maior concentração do país, ficando atrás apenas da Região Sudeste, com 67 emissoras em atividades. No entanto, observa-se entre as emissoras sulistas o menor índice de afiliação, se comparado às demais regiões brasileiras. São apenas quatro TVs que integram a rede pública, o que representa menos de $15 \%$ dos concessionários educativos ${ }^{2}$.

\section{Universalidade de acesso}

A universalidade é um dos princípios do serviço público. Refere-se ao dever do Estado em proporcionar a todos os cidadãos a mesma possibilidade de acesso a determinado serviço, neste caso específico: a recepção gratuita do sinal da televisão pública. O preceito da universalidade se equipara ao ideal de igualdade que deve estar expresso nas políticas de comunicação (McQuail, 1992). Essa é uma característica fundamental quando se pensa em serviço público, como destaca Antonio Pasquali (1991 p. 155): “Toda radiodifusão pública é por definição de alcance nacional. Ela presta exatamente o mesmo serviço a todos [...], garantindo ao morador da capital e ao habitante mais distante geograficamente que recebam os mesmos programas e nas mesmas condições" ${ }^{\prime \prime 3}$.

Tratar com equidade, sem discriminar por localização geográfica ou condição econômica, significa disponibilizar a programação no sinal aberto em todo o território nacional, preceito que ganha ainda maior relevância em contextos como o brasileiro, em que a densidade nacional da televisão por assinatura não ultrapassa a $30 \%$ da população. Entre as unidades da Federação há uma variação expressiva da penetração do serviço. O Distrito Federal registra a maior média nacional, densidade de 53,92\% por 100 domicílios, enquanto no Piauí a densidade cai para $7,96 \%$ da população que possui alguma modalidade de televisão paga $^{4}$. Os dados contribuem para sinalizar que qualquer projeto de constituição de uma rede televisiva de amplitude nacional passa necessariamente, nesse contexto, pelo sinal aberto e gratuito.

A estratégia que vem sendo adotada pela Empre- sa Brasil de Comunicação para garantir aos brasileiros a universalidade do sinal da TV Brasil tem sido pela construção da estrutura "em rede" baseada nas afiliações das TVs Educativas e com algumas emissoras próprias: Rio de Janeiro, Maranhão e São Paulo, além da sede em Brasília. "Chegar com a programação até as audiências, com sinal de qualidade comparável a qualquer outra televisão", este é um dos desafios para a TV Brasil nos próximos cinco anos na avaliação do pesquisador e membro do Conselho Curador da Empresa Brasil de Comunicação (EBC), Murilo César Ramos (2013) $)^{5}$. A universalização da cobertura constitui um dos maiores problemas da empresa pública porque não consegue levar a programação gratuitamente a todos os brasileiros. $O$ sinal atinge parcialmente a maioria dos Estados, porém não chegava até junho de 2016 aos estados de Rondônia e Amapá6.

O problema da universalização do sinal não conseguiu ser resolvido na primeira meia década de existência da $E B C$ e, desta forma, fere uma das concepções básicas do serviço público: a universalidade de acesso. Propiciar o acesso à programação nas mesmas condições técnicas em todo o país corresponde ao ideal de igualdade que deve nortear as políticas de comunicação (McQuail, 1992; Pasquali, 1991). E, neste quesito, o projeto de comunicação pública brasileira tem falhado.

Concessionários educativos na Região Sul

Há disparidade entre a distribuição das TVs Educativas entre os estados da região. A maior concentração ocorre no Paraná, onde estão 13 das 28 emissoras. Na sequência aparece Santa Catarina com nove emissoras e Rio Grande do Sul com seis. Se observada a relação entre a quantidade de TVs Educativas e afiliação à TV Brasil, o estado paranaense apresenta, proporcionalmente, o menor índice de emissoras associadas na Região Sul, 
apenas 7,7\% (quadro 01); por outro lado, o Rio Grande do Sul aparece com $16,7 \%$. Por fim, as TVs Educativas catarinenses apresentam o maior índice de afiliação. São duas associadas à rede pública, correspondentes a $22,2 \%$ das emissoras. Mesmo com maior proporção de afiliação na Região Sul, as emissoras catarinenses ficam abaixo da média nacional de associação, que é de $25,2 \%{ }^{7}$.

Desagregando os números para uma análise mais qualitativa, pode ser observada uma disparidade entre instituições privadas e públicas como concessionárias de TVs Educativas. Os entes privados, constituídos por diferentes grupos sociais - empresários/outros, políticos, universidades particulares e grupos ou organizações religiosas -, possuem 23 emissoras ou $82,1 \%$ do total. Apenas cinco canais educativos (17,9\%) estão sob o comando de entes públicos, entre eles: a) duas prefeituras, uma no Estado do Paraná e outra no Estado do Rio Grande do Sul; b) dois governos estaduais: o do Estado do Paraná e o do Rio Grande do Sul; e uma de universidade pública federal, no caso da UFSC.

Os dados apresentados revelam que ao se falar de TVs Educativas nesta região estamos nos referindo praticamente às emissoras controladas por "proprietários" particulares. É elevada a quantidade dessas TVs com vínculo particular quando comparadas àquelas concedidas para instituições públicas. Esse quadro é um dos reflexos da política de comunicação iniciada no governo de Fernando Henrique Cardoso (1995-2002), período no qual a distribuição das outorgas das emissoras comerciais passou a ser feita por meio de licitação, ao mesmo tempo em que se possibilitou aos canais educativos a geração de conteúdo local e inserção de apoio institucional - medidas essas que as tornaram mais viáveis para atender aos interesses de grupos privados locais.

De acordo com a tipologia adotada, baseada no

\begin{tabular}{|c|c|c|c|c|}
\hline Estado & $\mathbf{N}^{\circ}$ TVs & $\begin{array}{c}\text { TVs em relação à } \\
\text { região (\%) }\end{array}$ & $\begin{array}{c}\mathbf{N}^{\circ} \text { afiliadas } \\
\text { à TV Brasil }\end{array}$ & $\begin{array}{c}\text { \% afiliadas } \\
\text { no Estado }\end{array}$ \\
\hline PR & 13 & 46,4 & 1 & 7,7 \\
\hline RS & 6 & 21,4 & 1 & 16,7 \\
\hline SC & 9 & 32,1 & 2 & 22,2 \\
\hline $\begin{array}{c}\text { Total Região } \\
\text { Sul }\end{array}$ & $\mathbf{2 8}$ & $\mathbf{1 0 0}$ & $\mathbf{4}$ & - \\
\hline
\end{tabular}

Quadro 01: Emissoras e afiliação à TV Brasil, por Estado, na Região Sul Fonte: Anatel/Dados agregados pela autora

perfil do concessionário ${ }^{8}$, temos dois grupos de concessionários predominantes: a) Universidades Privadas; e b) Empresários/outros. Cada um deles detém 25,0\% das TVs Educativas da região, ou seja, sete concessões (figura 1). Na sequência vem o grupo Político com $14,3 \%$ dessas TVs, o que correspondente a quatro canais. As fundações mantidas por grupos religiosos possuem 17,9\% ou cinco emissoras. As prefeituras e governos estaduais aparecem em menor porcentagem, com 7,1\%, visto que cada um possui duas TVs. E, por último, constata-se a existência de uma universidade pública com apenas uma emissora, o que equivale a $3,6 \%$ do total de emissoras em funcionamento na região.

A análise dos grupos concessionários revela um cená- rio bastante complexo. O governo federal não adotou critérios transparentes para repassar as outorgas educativas aos concessionários e, ante a isso, acabou beneficiando grupos privados que, em princípio, não tinham e ainda não têm nenhuma ou quase nenhuma afinidade com as TVs Educativas. Some-se a isso o fato de também não existirem mecanismos de controle fiscalizatório sobre o uso que esses concessionários fazem dessas emissoras.

Se observada a forma como foram entregues as outorgas pelo Estado brasileiro, poucas universidades públicas as receberam na região e somente a UFSC possui concessão. Com isso, não quero apontar que emissoras nas mãos de entes públicos como, por exemplo, governos estaduais ou municipais sejam "puras", livres de in- 
gerências e interesses políticos, econômicos, religiosos, entre outros, isto é, que elas não sejam utilizadas para fins políticos que destoam dos princípios aqui discutidos para as TVs públicas. Contudo, ao que parece, predominam critérios político-econômicos para a sua concessão.

Verificando-se o perfil dos concessionários por estado, o Paraná apresenta o quadro mais grave. Entre as suas 13 emissoras, duas delas pertencem ao grupo que designamos de Religioso católico, denominado "Fundação Evangelizar é Preciso", do padre Reginaldo Manzotti. São elas a TV $3^{\circ}$ Milênio de Curitiba e a TV $3^{\circ}$ Milênio de Maringá. Contudo, a referida fundação não é de fato a concessionária, essas foram arrendadas da Fundação Champagnat de Curitiba e da Fundação Nossa Senhora de Lourdes de Maringá. Deve-se destacar que a Fundação Evangelizar é Preciso projeta se consolidar como uma rede regional de televisão católica, visto que no final de 2012 possuía 60 retransmissoras que levavam a sua programação a 431 cidades paranaenses.

Um pouco maior que o grupo Religioso aparece o grupo classificado como Político, com três emissoras educativas no Paraná. Uma delas é a TV Cultura Norte Paranaense (Rolândia), que lançou sua diretora, Flávia de Paula, como candidata à prefeitura dessa cidade, pelo Partido Democrático Trabalhista (PDT), em 2008. A candidata foi condenada judicialmente por abuso de poder econômico e uso indevido de meio de comunicação, ficando inelegível por três anos. Além disso, a emissora foi multada por beneficiar a candidata supracitada em sua programação. Um dos sócios da TV Alvorada (Colorado), Antônio João Manzano, se candidatou pelo Partido da Social Democracia Brasileira (PSDB) a vice-prefeito do Município de Colorado. Ele foi eleito para esse cargo e o exerceu de 2008 a 2012. Outra TV Educativa do Estado do Paraná que classifi-

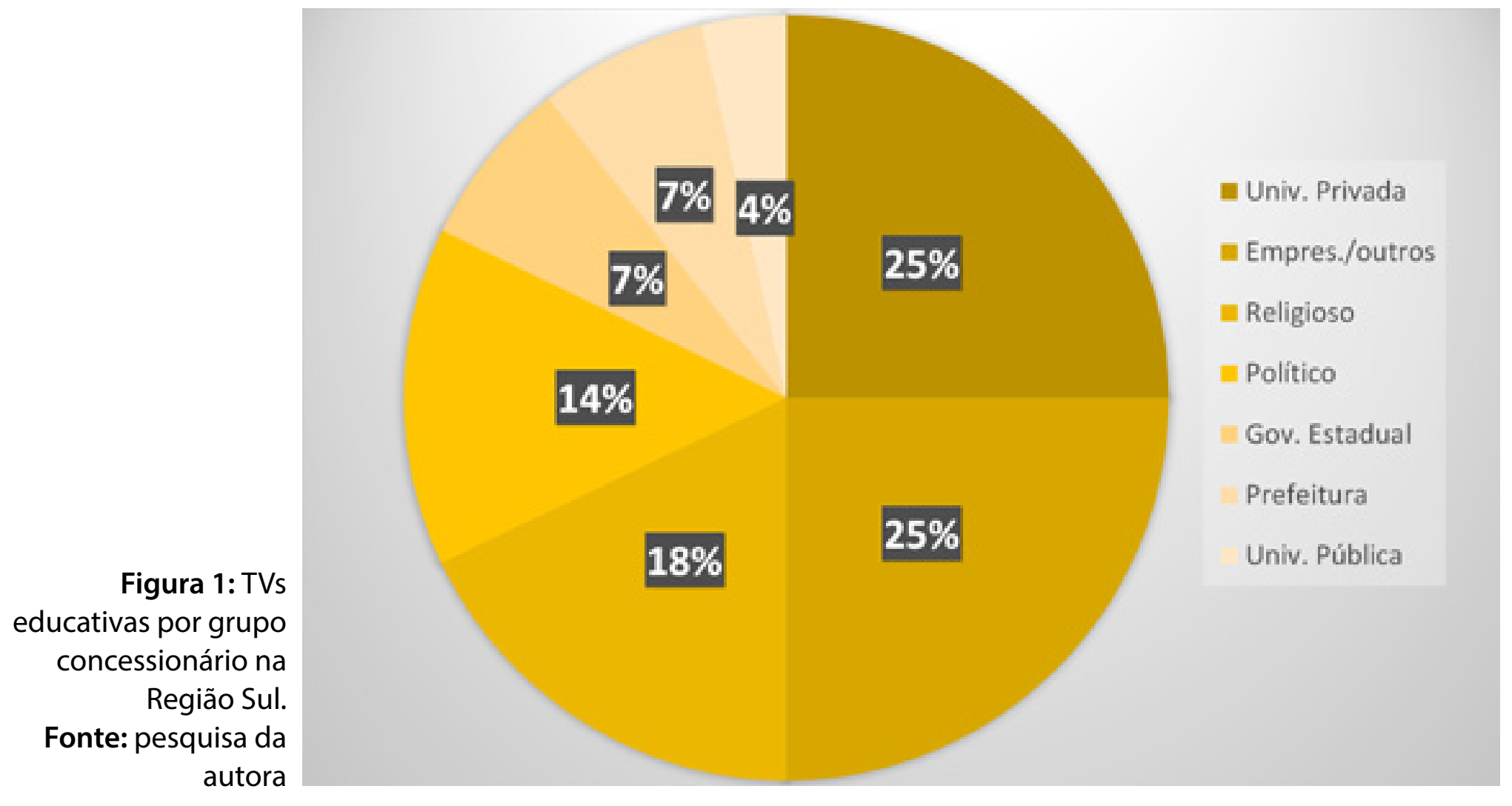

camos como do grupo Político é a TV Milenium (União da Vitória), em que um dos seus sócios, Airton Roveda Filho, ocupou o cargo de prefeito desse município e deputado federal, tendo passagem por vários partidos políticos, tais como PMDB, PFL, PT e PR.

No grupo Empresários/outros encontram-se a TV Carajás (Campo Mourão), assim como a CATVE (Cascavel), que integra o grupo de comunicação de Jorge Guirado, que também é "proprietário" da TV Tarobá (Londrina). Deve-se destacar que essa última é uma concessão comercial afiliada à Rede Bandeirantes. A terceira integrante do grupo Empresários/outros é a TV Cultura Cinturão Verde (Cianorte) e pertencente à Fundação Antonio Bar- bara, também proprietária da rádio educativa Olga FM. Nesse grupo Empresários/outros inclui-se também a TV Caiuá (Assis Chateaubriand). Negociada e/ou vendida várias vezes, essa emissora educativa passou por vários donos e em uma das gestões foi denominada TV Piquiri, que retransmitia a Rede TV. Por último, faz parte do grupo que categorizei de Empresários/outros a TV Beltrão (Francisco Beltrão), que é a única emissora educativa afiliada à TV Brasil no Paraná.

Há ainda no estado do Paraná um grupo designado de "Universidade Privada". Nele está a TV Unipar, que pertence à Universidade Unipar, uma instituição de ensino superior privada, localizada no município 
de Umuarama. Finalizando essa análise relativa ao Estado do Paraná, chama atenção o dado de que a única emissora educativa afiliada à TV Brasil neste Estado seja privada, como visto anteriormente, embora haja nesta Unidade da Federação brasileira duas emissoras que são propriedades públicas: a) a EPR com sede no Município de Curitiba, vinculada ao governo estadual; e b) a TVE Ponta Grossa, que pertence à prefeitura desta cidade. Esses dados são importantes para se refletir sobre a resistência à afiliação das TVs Educativas à TV Brasil. Poderia supor que a recusa à associação se deve basicamente ao fato de as emissoras educativas do Estado terem, em sua maioria, vínculo privado. Contudo, não me parece ser fator preponderante o tipo de vínculo, se privado ou público, para justificar a resistência de afiliação à TV Brasil, pois nenhuma das duas TVs educativas paranaenses com vínculo público é afiliada à TV Brasil.

Comparativamente ao Paraná, o Rio Grande do Sul possui um cenário aparentemente mais homogêneo em relação aos perfis dos grupos concessionários, provavelmente porque o estado gaúcho tem menos da metade da quantidade de TVs Educativas que o paranaense, mas, principalmente, porque no Rio Grande do Sul há uma concentração das TVs Educativas nas universidades privadas. Mas, como o estado do Paraná, o Rio Grande do Sul tem duas TVs Educativas públicas. Uma delas é a TVE-RS, com sede na capital, pertencente ao governo estadual. A outra é a TV Cultura, localizada no município de Montenegro, que é o concessionário. As demais emissoras, quatro, são classificadas no grupo Universidades Privadas: a) UCS TV da Universidade de Caxias do Sul; b) UPF TV da Universidade de Passo Fundo; c) Unisinos TV da Universidade do Vale dos Sinos; e d) a Ulbra TV da Universidade Luterana do Brasil. Como se observa, ao contrário do estado do Paraná, sem grande diversidade de tipolo- gias classificatórias de TVs Educativas, assim como, sem aparente contradição, a única TV Educativa do Estado do Rio Grande do Sul afiliada à TV Brasil é uma emissora que tem vínculo público, a TVE-RS.

Em Santa Catarina foram encontrados cinco tipos de grupos concessionários, aproximando-se do Paraná no que diz respeito à diversificação de tipologias. Enquanto no Paraná o grupo que tem maior quantidade de TVs Educativas é o Empresarial/outros, em Santa Catarina é o Religioso, com três emissoras. Duas delas pertencem à Igreja Neopentecostal Centro Evangelístico de Itajal (CEI), que criou a Fundação Educacional e Cultural de Itajaí, mantenedora das TVs Brasil Esperança nas cidades de Joinville e Itajaí. A terceira TV Educativa do grupo Religioso desse Estado tem como concessionário a Fundação Educar Sul-Brasil, com sede em Florianópolis. Contudo, essa concessão foi arrendada à TV Canção Nova. Até o final de 2013, atuava apenas como retransmissora da programação gerada pela Canção Nova de São Paulo, mas com a previsão de produzir conteúdo local, em Florianópolis, a partir do ano de 2014.

No grupo classificado como Político há apenas uma emissora em Santa Catarina, a TV Panorama, localizada em Balneário Camboriú. Mantida pela Fundação de Radiodifusão Rodesindo Pavan, que pertence ao exsenador que também foi vice-governador do Estado, Leonel Pavan (PSDB). Antes de possuir a TV Panorama, o seu proprietário já era político profissional, tendo sido prefeito por três mandatos.

Duas TVs Educativas foram inseridas no grupo denominado de Empresarial/outros, a ARTV, de Araranguá, pertencente à Fundação Ângelo Redivo, assim como a Rede Bela Aliança, com sede na cidade Rio do Sul, da Fundação Osny José Gonçalves. Essa última, antes de requerer a concessão educativa, já possuía duas outras concessões: a Rádio Mi- rador AM e a Rádio 93FM. Isto nos indica que a concessão educativa foi adquirida provavelmente para ampliar, por meio de outro meio de comunicação de massa, o grupo de comunicação iniciado com as rádios supracitadas.

Por fim, o grupo denominado de Universidade Privada é formado pelas TV FURB, da Universidade Regional de Blumenau; e a TV Unisul, mantida pela Universidade do Sul de Santa Catarina de Tubarão. Vale destacar que esta última foi concessão feita durante o governo Lula, em 2003. Há ainda a recém-implantada, em canal aberto, UFSC TV. Essa emissora estava disponível somente na transmissão a cabo até maio de 2013, quando iniciou a transmissão também pelo canal aberto.

O grupo denominado Empresarial/outros também tem uma quantidade significativa de TVs Educativas no Paraná, com 38,4\% do total, correspondendo a quase três vezes mais a porcentagem encontrada em Santa Catarina. Os três grupos (Político, Religioso e Empresarial) não foram encontrados como concessionários no Rio Grande do Sul. Em contrapartida, as universidades privadas concentram a propriedade das TVs Educativas no Estado gaúcho, detendo $66,7 \%$ das concessões. As instituições públicas, conforme já mencionado, são minoritárias no comando das TVs Educativas nos três estados.

A partir da análise do perfil do concessionário, se levarmos em consideração a definição de Valente (2009), de que apenas as emissoras mantidas e administradas pela União, Estados e municípios deveriam ser consideradas como públicas, teríamos uma parcela bastante reduzida incluída nesta denominação, menos de $18 \%$ das TVs Educativas da região. Por outro lado, o levantamento feito aponta para a privatização dos canais educativos, uma vez que em sua grande maioria estão em mãos de fundações com perfil religioso, político ou empresarial.

Essa situação começou a ser desenhada entre 1988 e 
2002, período no qual 24 das 28 TVs Educativas da região foram outorgadas pelo governo de Fernando Henrique Cardoso. Entre as outras quatro emissoras em funcionamento, duas tiveram outorgas anteriores ao período citado, a EPR e a TVE-RS; e duas outras posteriores: a Unisul TV (2003) e a UFSC TV (2013). Embora o cenário apresentado tenha sido construído predominantemente durante o governo do PSDB, isso em nada exime a responsabilidade pela sua manutenção durante os 11 anos posteriores da administração petista. Portanto, essa prática foi iniciada no final da década de 1990, com a administração FHC, e não foi alterada nos dois governos do presidente Luiz Inácio Lula da Silva (2003-2010) e tampouco no governo da presidente Dilma Rousseff. O que é um claro sinal da opção por manter a falta de critérios para repassar as outorgas educativas aos concessionários, assim como da falta de fiscalização ou, em outras palavras, da ausência de medidas eficazes para regular a radiodifusão brasileira e, especificamente, a pública. Às emissoras que estão em funcionamento não foram implementadas normas para avaliar o desempenho para renovação das outorgas, o que pode indicar que terminados os prazos de 15 anos das concessões distribuídas entre 1998 e 2002, essas serão renovadas, sem maiores complicações.

\section{A presença da rede pública na Região Sul}

$\mathrm{O}$ baixo índice de afiliação à TV Brasil pode estar relacionado ao domínio privado das concessões Educativas na Região Sul. Nesse espaço temporal de quase 10 anos da implantação da EBC não houve avanços significativos em relação à ampliação da cobertura. No início das atividades da TV Brasil, em 2007, a programação chegava à região através da TV Educativa do Paraná, atual EPR, e da TV Cultura Santa Catarina - desativada

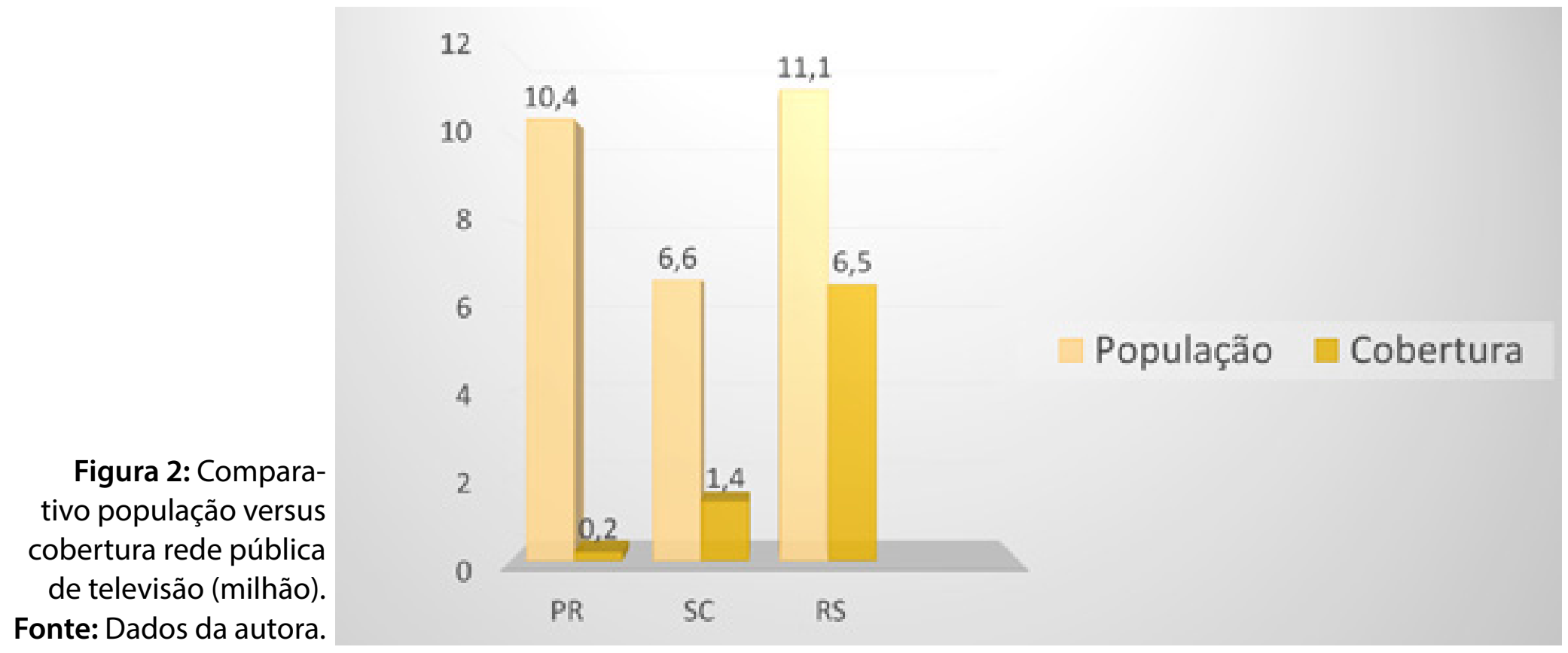

em 2009. A eleição de 2010 reduziu a cobertura da rede Paraná e ampliou no Rio Grande do Sul, estados onde as TVs Educativas estão vinculadas aos governos estaduais e, consequentemente, acabam sendo mais vulneráveis às decisões políticas. Com a eleição no estado paranense de Beto Richa (PSDB), oposição ao governo petista, a direção optou pela desvinculação da TV Brasil e adotou como cabeça-de-rede a TV Cultura de São Paulo. O contrário ocorreu no Rio Grande do Sul, a vitória de Tarso Genro (PT) resultou na rescisão do contrato com a emissora paulista e no início da retransmissão do conteúdo da TV Brasil. A situação foi mantida na eleição de 2014 com a continuidade de Richa, no Paraná, e eleição no Rio Grande do Sul de José Ivo Sartori (PMDB).

O universo de afiliadas à TV Brasil na Região Sul ébastante restrito. São apenas quatro as emissoras que integram a rede nacional, contudo existem diferenças consideráveis entre elas. Duas delas são entidades sem fins lucrativos de direito
privado:TV Beltrão (Francisco Beltrão/PR) e ARTV (Araranguá/ SC). A TVE-RS (Porto Alegre/RS) está vinculada ao governo estadual, enquanto a UFSC TV (Florianópolis/SC) faz parte da estrutura organizacional da Universidade Federal de Santa Catarina. A distinção não fica apenas no formato jurídico, mas reverbera principalmente na característica do conteúdo produzido e/ou inserido na grade local e até na estrutura física.

Uma das particularidades é a abrangência da cobertura do sinal que é mais ampla entre as afiliadas vinculadas a instituições públicas, provavelmente porque houve investimentos públicos e as TVs pertencentes às fundações privadas têm dificuldades financeiras para ampliar a cobertura. No caso do Paraná, a única afiliada é a TV Beltrão de Francisco Beltrão, maior munícipio da Região Sudoeste, que possui 80,7 mil habitantes (IBGE, 2010). Segundo seu diretor, Valmor Merísio (2013), a emissora tem outro retransmissor na cidade de Marmeleiro e consegue chegar a outras 11 cidades vizinhas. 
A TV Beltrão atinge no máximo 200 mil moradores desta microrregião, isto significa que a programação da TV Brasil chega através desta afiliada a menos de $2 \%$ da população paranaense, calculada em 10,4 milhões pelo último recenseamento (IBGE, 2010). Diante deste quadro, podese considerar que a RNCP tem alcance pouco expressivo no Estado, ou pior, reduziu significativamente seu alcance com a saída da TVE PR (atual EPR) a partir do início de 2011. A EPR chega a $60 \%$ do território paranaense.

O fato ocorrido no Paraná suscita o debate sobre a fragilidade da rede pública de televisão, ainda mais se considerado que 14 emissoras integrantes da rede nacional estão vinculadas aos governos estaduais 9 . Isso pode ser um indício de que a cada quatro anos, com a realização de eleições para o Executivo estadual, dependendo do governador eleito, pode haver ampliação ou redução da RNCP. Além do mais, aponta a identificação da TV Brasil como uma televisão governamental à qual não querem estar vinculados os governadores dos partidos de oposição. Como lidar com este cenário, se desvencilhar da sigla partidária para dar maior consolidação ao projeto de rede?

A mesma eleição que reduziu a rede no Paraná ampliou a cobertura no Rio Grande do Sul, aonde a TV Brasil não chegava pelo sinal aberto até 2011. Segundo o ex- Presidente da Fundação Piratini (Rádio e TVE-RS), Pedro Osório (2011), a emissora não tinha condições de arcar com o custo de R\$ 25 mil cobrado pela TV Cultura de São Paulo. Serviu de motivação a possibilidade de trocar conteúdos com outras integrantes da rede e, assim, ter a produção local gaúcha veiculada nacionalmente ou em outras regiões do país. É neste estado que a rede pública tem o maior alcance na Região Sul. A TVE-RS atinge aproximadamente 6,5 milhões, cerca de $60 \%$ dos 11,1 miIhões de habitantes, por meio de 40 antenas repetidoras e da geradora em Porto Alegre. A intenção da direção, segundo Pedro Osório (2011), é ampliar ainda mais a cobertura com investimentos em tecnologia, fazendo com que a rede seja recebida por mais de 8 milhões de pessoas, ou cerca de $80 \%$ da população do Estado até 2014. "Esses números colocam a TVE como a segunda maior emissora de televisão do Rio Grande do Sul" (Osório, 2011).

Em Santa Catarina, a TV Cultura SC (Florianópolis) foi a pioneira na retransmissão dos conteúdos da TV Brasil e a primeira emissora educativa do Estado, outorgada em 1994 à Fundação Catarinense de Difusão Educativa e Cultural Jerônimo Coelho, entidade criada pelas Universidade Federal de Santa Catarina (UFSC) e Universidade Estadual de Santa Catarina (Udesc). Com o seu fechamento, a TV Brasil ficou por cerca de dois anos sem cobertura no Estado até a incorporação da ARTV (Ângelo Redivo TV) à rede, em 2011.

A ARTV fica em Araranguá, cidade do Sul catarinense com 62 mil habitantes. A cobertura do sinal chega aproximadamente a 400 mil pessoas ou $6 \%$ da população catarinense, que é de 6,6 milhões (IBGE, 2010) ${ }^{10}$. Até 2011 esta emissora era afiliada à TV Cultura de São Paulo. Segundo a diretora comercial, Taiane Redivo, a desvinculação da emissora paulista foi motivada pela cobrança dos conteúdos e pela exigência de veiculação de muitos horários da rede, enquanto a TV Brasil dá maior autonomia à afiliada.

Recentemente, a TV Brasil conseguiu ampliar sua cobertura em Santa Catarina quando a UFSC TV, em maio de 2013, começou a ser transmitida no canal aberto em substituição a TV Cultura SC. O sinal da nova afiliada cobre a região metropolitana de Florianópolis, formada por nove municípios, que juntos somam cerca de 1 milhão de habitantes, ou algo em torno de $16 \%$ dos catarinenses.
Na figura 2, é possível visualizar com mais clareza a presença da TV Brasil na Região Sul por meio das suas afiliadas. Em nenhum dos estados a Rede Nacional de Comunicação Pública (RNCP) está sequer próxima de ter o sinal universalizado. A rede está em melhor situação no Rio Grande do Sul, onde chega a $60 \%$ da população. As duas emissoras catarinenses conseguem atingir cerca de $22 \%$ dos moradores do Estado, enquanto o Paraná apresenta o quadro mais crítico, o sinal alcança somente a $2 \%$ dos paranaenses.

Se comparado o cenário atual com aquele encontrado no primeiro ano de funcionamento da TV Brasil na Região, houve avanço na cobertura do sinal no Rio Grande do Sul, Estado em que a cobertura era inexistente e chegou a $60 \%$. No Estado catarinense, com o fechamento da TV Cultura SC houve uma fase sem nenhuma afiliada, entre 2009 e 2011. Posteriormente, a ARTV integrou a rede e mais recentemente a UFSC TV. O incremento ocorreu de fato no Sul do Estado com a cobertura sendo estendida a mais 400 mil pessoas. Apesar de estar concentrado no Paraná o maior número de TVs Educativas da região, 13, é este Estado com o menor índice de afiliação e com a mais restrita penetração da TV Brasil. É o único da região em que a situação piorou depois de cinco anos.

\section{Considerações finais}

A TV Brasil aproxima-se da sua primeira década com dificuldade de nacionalizar o acesso. Sem agregar afiliadas, fragiliza a consolidação da rede nacional de comunicação pública por não conseguir disponibilizar o sinal gratuito em todo o território nacional. Como a programação não chega à grande maioria das localidades, criou-se uma emissora pública desprovida de potencial para ter audiência. Excluindo a possibilidade de a população ter acesso à programação, fere-se uma 
concepção básica do serviço público, inclusive da comunicação: a universalidade de acesso.

A pesquisa realizada com os concessionários educativos na Região Sul evidenciou três problemas que prejudicam a ampliação da rede pública. São eles:

1) Regularidade - a afiliação não poderá ocorrer se a emissora tiver algum tipo de débito com a União. Isso implica estar adimplente com as obrigações fiscais, como o pagamento da previdência social. A regra é válida para empresas e/ou instituições firmarem qualquer tipo de contrato, convênio ou cooperação com a União. A simples existência desta norma já põe em xeque o projeto de ampliação da cobertura da TV Brasil condicionado a afiliação das TVs Educativas, afinal, não há como garantir que as emissoras estejam em dia com suas obrigações. Como esse problema foge do controle dos gestores da emissora federal, é algo que cabe ao concessionário resolvê-lo.

2) Afiliação voluntária - embora a concessão seja educativa (não comercial), as fundações concessionárias, assim como qualquer outra emissora, possuem autonomia para escolher a cabeça-de-rede com a qual irão trabalhar associadas. Cabe relembrar que as outorgas educativas são distribuídas sem licitação e gratuitamente às fundações sem fins lucrativos. Além desse privilégio, os concessionários ainda podem receber incentivos ou deduções dos tributos quando obtêm o título de utilidade pública municipal, estadual ou nacional. Desta forma, o Estado é útil para conceder benefícios, mas quando é para estabelecer relacionamento, por meio da afiliação, deixa-o de ser.

A maior contradição reside no fato de essas emissoras, que deveriam ser parceiras da TV Brasil, levando o sinal a maior número de brasileiros, estarem contribuindo com a expansão de grupos privados de comunicação. Servem para ilustrar os casos da SESC TV, mantida pelo empresa- riado do comércio; Rede Mercosul, televisão comercial de propriedade de Luis Mussi, político vinculado ao PMDB; Rede Século 21, televisão católica. Com a presença mais significativa vem o Canal Futura, pertencente à Fundação Roberto Marinho das Organizações Globo, que tem como mantenedores organizações comerciais e grandes conglomerados financeiros e industriais.

3) Divergência político-ideológica - a maioria dos gestores das TVs Educativas não explicita que a diferença política com o governo petista desmotiva a afiliação, contudo, as atitudes indicam a preferência em não vincular suas emissoras à imagem do governo federal. Algumas delas eram afiliadas à antiga TVE-RJ, mas com a sua junção para formar a nova rede, houve desfiliação de quatro emissoras catarinenses e uma paranaense. Outro aspecto que indica a divergência é que há concessionários que preferem pagar à TV Cultura de São Paulo pelo uso do conteúdo a receber a programação gratuita da TV Brasil.

As dificuldades para construir a rede pública na $\mathrm{Re}$ gião Sul e no Brasil, provavelmente, passarão por outros desafios a partir do governo Michel Temer (PMDB), que substitui a presidenta afastada, Dilma Rousseff. No curto período de Temer como presidente, foi possível perceber a tentativa de desmonte da EBC. Primeiro com a demissão do presidente da EBC, jornalista Ricardo Melo, e depois com a alteração da lei no 12.652 /2008, que instituiu os princípios da radiodifusão pública e criou a EBC. As mudanças implementadas por meio da medida provisória 744/2016 fragilizam o caráter público da EBC e retiram a garantia do mandato de quatro anos do diretor-presidente da empresa pública. Isso significa, por exemplo, que o governo federal poderá exonerar o presidente da EBC se a linha editorial não atender aos interesses gover- namentais. A MP também extinguiu o Conselho Curador que era formado por 15 representantes da sociedade civil, um representante dos trabalhadores da EBC, quatro do governo federal, um do congresso. Essa medida também enfraquece o caráter público da EBC, deixa a empresa suscetível aos desmandos do governo.

\section{Referências bibliográficas}

ANATEL. TV paga fecha fevereiro de 2016 com 18,96 milhões de assinantes. Disponível em: http://www.anatel.gov.br/Portal/exibirPortalNoticias. do?acao=carregaNoticia\&codigo=39010. Acesso em: 10 jun. 2016.

CRUVINEL, Tereza. 4 anos de um ideal democrático: EBC - Empresa Brasil de Comunicação. Brasília, 2011.

IBGE. Síntese por Estado. Disponível em: <http://www. ibge.gov.br/estadosat/perfil.php?sigla=sc>. Acesso em: 20 nov. 2012.

LOPES, Ivonete da Silva. TV Brasil e a construção da rede nacional de televisão pública. Jundiaí: Paco Editorial, 2015.

MCQUAIL, Denis. La acción de los medios de comunicación y el interés público. Londres: Sage, 1992.

OSÓRIO, Pedro. Entrevista concedida a Ivonete da Silva Lopes, Porto Alegre, nov. 2011 e dez. 2013.

PASQUALI, Antonio. El orden reina. Escritos sobre comunicaciones. Caracas: Monte Avila, 1991. 
RAMOS, Murilo César. EBC: os avanços e os desafios depois de meia década. [entrevista concedida a Ivonete da Silva Lopes]. Revista Eptic [online], Aracaju, vol.15, n.2, p. 6-11, mai-ago 2013.

TV BRASIL. Como sintonizar. Disponível em: <http:// tvbrasil.ebc.com.br/comosintonizar $>$. Acesso em: 20 jun. 2016.

VALENTE, Jonas. TV pública no Brasil - a criação da TV Brasil e sua inserção no modo de regulação setorial da televisão brasileira. 2009. 210 f. Dissertação (Mestrado em Comunicação) - Faculdade de Comunicação, UNB, Brasília, 2009.

WEBER, Max. Ensaios de sociologia. Rio de Janeiro: Zahar, 1991.

\section{Notas}

1 Doutora em Comunicação pela Universidade Federal Fluminense. Docente da Universidade Federal de Viçosa (UFV) (Avenida Peter Henry Rolfs, s/n, Campus Universitário, Viçosa/MG, Brasil, CEP: 36570-900). E-mail: ivonetesilvalopes@gmail.com

2 As regiões brasileiras com menor quantidade de concessões educativas aparecem com maior porcentual de afiliação, como são os casos da região Norte, que possui seis TVs Educativas e cinco delas $(83,3 \%)$ integram a rede; Centro-Oeste com 12 emissoras e três afiliadas (25\%); Nordeste com 24 e nove afiliadas (37,5\%). Do lado aposto vem a região Sudeste onde se concentra a maioria desses canais; são 67 e, desses, 13 estão associados, representando 19,5\%. 0 menor índice de afiliação ocorre na região Sul, que detém o segundo lugar na quantidade de TVs Educativas, são 28 em funcionamento, entretanto proporcionalmente é a área do país com o menor índice de afiliação, são meramente quatro $(14,3 \%)$ dos concessionários educativos da região que integram a rede pública de comunicação (Lopes, 2015).

3 Tradução livre feita pela autora de: "toda radiodifussuión pública es por definición de alcance nacional. Ella presta exactamente el mismo servicio a todos [...], garantizado al capitalino y al habitante de más alejado recodo geográfico que recibirán los mismos programas en las mismas condiciones" (PASQUALI, 1991, p. 155).

4 Conforme a estatística apresentada pela Agência Nacional de Telecomunicações (Anatel) em março de 2016. Disponível em: <http://www.anatel.gov.br/Portal/exibirPortalNoticias.do?acao $=$ carregaNoticia\&codigo $=39010>$.

5 EBC: avanços e desafios depois de meia década, entrevista concedida pelo Dr. Murilo César Ramos a esta autora. Disponível em: <http://www.seer.ufs.br/index.php/ eptic/article/view/935/827>.

6 Disponível em: <http://tvbrasil.ebc.com.br/comosintonizar>.

7 Síntese população por Estado. Disponível em: <http:// www.ibge.gov.br/estadosat/perfil.php?sigla=sc>.

8 A tipologia criada por Lopes (2015) foi feita baseada no quadro societário de cada emissora, de acordo com dados da Agência Nacional de Telecomunicações (Anatel). Afirma a autora que a classificação possui uma intenção didática, não querendo apontar para a existência de grupos puros. Um tipo ideal, não uma forma pura na realidade, trata-se de uma construção teórica construída a partir de uma intensificação de alguns aspectos da realidade (Weber, 1991).

9 Síntese população por Estado. Disponível em: <http:// www.ibge.gov.br/estadosat/perfil.php?sigla=sc> 